\title{
Inert Copper Ion Complexes Formed by Humic Acids
}

\author{
Ragnar Österberg, ${ }^{*}$ Shiqiang Wei and Ludmilla Shirshova
}

Department of Chemistry, Swedish University of Agricultural Sciences, PO Box 7015, S-750 07 Uppsala, Sweden

\begin{abstract}
Österberg, R., Wei, S. and Shirshova, L., 1999. Inert Copper Ion Complexes Formed by Humic Acids. - Acta Chem. Scand. 53: 172 180. (C) Acta Chemica Scandinavica 1999.

In the $\mathrm{pH}$ range $7-2.6$ copper ions form inert complexes with humic acids, which may be bound to intraparticle binding sites. This is shown by emf studies using glass and $\mathrm{Cu}$-sensitive electrodes at $24^{\circ} \mathrm{C}$ and $0.1 \mathrm{M} \mathrm{NaClO}_{4}$ medium. Solutions of $\mathrm{Cu}^{\mathrm{II}},(0.1-0.33 \mathrm{mM})$ and humic acids $\left(1-2 \mathrm{~g}^{-1}\right)$ were titrated with $\mathrm{HClO}_{4}$ in an oxygen-free atmosphere. At each point the data were recorded after reaching a steady state (after $6-24 \mathrm{~h}$ ) as indicated by a redox electrode. Kinetic data indicate that the metal ion interaction involves diffusion into the humic acid particles; the rate-limiting step appears to be the diffusion through the boundary layer surrounding the particles (film diffusion). For total $\mathrm{Cu}$ concentrations $\leqslant 0.24 \mathrm{mM}, \mathrm{Cu}$ ions seem to be bound in four-coordinate sites. since four protons are released per $\mathrm{Cu}$ ion. However, somewhat fewer protons are released $(\geqslant 3)$ for the highest copper concentrations $(0.33 \mathrm{mM})$ as well as for the lowest humic acid concentration $\left(1 \mathrm{~g} \mathrm{l}^{-1}\right)$. In addition, a small fraction of the copper ions forms a labile $\mathrm{CuA}$ complex with $\log \beta_{1}=5.3$, most likely involving the coordination of two carboxylates. (Here $\mathrm{A}$ is the binding site of humic acids.) The proton reactions of humic acids, studied under the same conditions, are consistent with the titration of three acid-base groups of apparent $\mathrm{p} K$-values, $5.8,3.8_{5}$ and 1.6 , and a $\mathrm{HA}_{2}$ 'dimer' involving hydrogen bonds of the particles.
\end{abstract}

Humic substances in soil and natural water systems constitute the important organic interphase between living matter and inorganic material. The capacity of humic and fulvic acids to bind metal ions make them important agents for the speciation and the mobility of metal ions into the plant and animal kingdoms. The importance of this matter has encouraged a large number of studies intended to predict the role of humic substances in the utilization and storage of metal ions; for a summary on this subject see the compilations by Frimmel and Christman $^{1}$ and by Hayes et al.; ${ }^{2}$ cf. Perdue and Gjessing. ${ }^{3}$

Numerous studies have been devoted to the analysis of proton and metal ion reactions of humic acids in the form of prevailing complexes and their stability constants of formation (see for instance Refs. 4-10); for a summary of early literature see Refs. 11-13. However, there are fairly large variations among the results reported, which to a certain extent may be due to the different sources and methods of preparation used for the samples studied. There are also other factors which may explain this variation: (1) the humic acid system is kinetic in the sense that it is not at a thermodynamic equilibrium and at best a steady-state can be reached after some hours

\footnotetext{
$\dagger$ Presented in part at the 6th Nordic Symposium on Humic Substances, Tavastehus, Finland, June 1997.

* To whom correspondence should be addressed.
}

or usually in one day;,14-16 (2) autocatalytic polymerization due to oxygen ${ }^{17}$ and/or side reactions due to the addition of $\mathrm{OH}^{-}$(Ref. 18) may successively change the structure during a titration; for instance, forward and backward $\mathrm{pH}$ titrations show a marked hysteresis; ${ }^{7}$ (3) an impenetrable sphere has been generally used as a model for humic acid particles, although kinetic data show that metal ions diffuse into the particles; ${ }^{19,20}$ (4) as pointed out by Sposito et $a l^{21}$ (see citations therein), many of the authors have not analyzed their data by proper methods. Marinsky and Ephraim ${ }^{22}$ and Batschat et al. $^{23}$ discussed the matter of penetrable particles in some detail; nevertheless, both these American groups used impenetrable models in their data analysis.

In 1992 we reported that the neutron scattering from humic acids obeys a power law, indicating that the particles in solution are fractal ${ }^{14}$ the fractal dimension was determined to be 2.3 (cf. Refs. 15 and 24). These results, as well as atomic force microscopic data, ${ }^{25}$ indicated that particles of the size $100-300 \mathrm{~nm}$ dominate in solution. Furthermore, the partial collapse of the particles on the microscopic plate indicated that they mainly consist of water; the fractal dimension yields $>92 \%$ water. This high water content is in agreement with water analyses of peat, indicating it to be up to $90 \%$ water $^{26}$ (peat contains about $60 \%$ humic acids on a dry weight basis). Thus, as far as humic acids are concerned, there 
is no reason to assume that the particles in solution are 'compact' and impenetrable.

Assuming an ion-exchange mechanism, metal-ion diffusion into peat and humic acids particles have been studied by Kadlec and Keolian ${ }^{19}$ and by Bunzl et $a l^{20,27,28}$ Based on the theory developed by Hefferich $^{29-31}$ intraparticle diffusion was found to be rate limiting for certain peat particles. ${ }^{19}$ Bunzl et al. ${ }^{20}$ on the other hand, found that the rate of metal ion exchange in humic acids was film-diffusion controlled. The film is supposed to be the boundary layer between a particle and the bulk solvent. According to these authors and their mathematical analyses, ${ }^{19,20,27,28}$ large particles would favour intraparticle diffusion, and small particles (say $<1 \mu \mathrm{m}$ ) would favour film diffusion. An ionexchange model is of course a highly simplified way of describing the complex humic acid system, which most likely contains weakly acidic groups both inside the particles as well as on their surfaces. Nevertheless, these early studies ${ }^{19,20}$ have provided a guideline for the understanding of metal ion-humic acid interactions.

In this study, which deals with the copper ion interactions of humic acids, the data were recorded anaerobicly at a steady state as controlled by a redox electrode. The complex formation was measured by successively decreasing the $\mathrm{pH}$ of a dialysed sample of $\mathrm{pH} 7$ using perchloric acid. In this way possible structural changes due to oxygen or $\mathrm{OH}^{-}$ions were avoided, and the humic acid particles could be kept in a homogenous solution during the titration. The main results indicate that humic acids form inert copper ion complexes in the range $\mathrm{pH}$ 7-2.6. This may involve intraparticle binding sites, since kinetic data indicate that metal ion-humic acid interactions involve diffusion into the particles. In the kinetic part of this study calcium ions were used, since the fast kinetics of their reactions are readily distinguished from diffusion.

\section{Method}

Special approach for studying humic acid metal complexes. The humic acid system is a redox system characterized by a high sensitivity to oxygen and by non-equilibrium behaviour. ${ }^{4,14-16}$ However, under carefully controlled anaerobic conditions the system can be brought to a steady state, where the measured redox potential is a linear function of $\mathrm{pH}$ (see Fig. 2 in Ref. 16). From the redox diagram reported previously (see Fig. 5 in Ref. 16) it follows that the $\mathrm{Cu}^{\mathrm{II}} / \mathrm{Cu}^{\mathrm{I}}$ couple has a lower redox potential than that of humic acids in the acid and neutral $\mathrm{pH}$ range. Thus, in these ranges copper(II) ions are not reduced by humic acids. However, if $\mathrm{Cu}^{\mathrm{I}}$ were to form humic acid complexes, which are considerably stronger than those of copper(II), then $\mathrm{Cu}^{\text {II }}$ would be reduced and then $\mathrm{Cu}^{\mathrm{I}}$ complexes would predominate in the solution.
Theory. For the present range of total molar concentration of copper ions, $B,=0.1-0.33 \mathrm{mM}$, we may assume that $\mathrm{Cu}^{\mathrm{II}}$ and humic acids react according to the general reactions:

$p \mathrm{Cu}^{2+}+r \mathrm{H}_{q} \mathrm{~A} \rightarrow \mathrm{Cu}_{p} \mathrm{~A}_{r}+(q r) \mathrm{H}^{+}$

$(q=0,1,2, \ldots)$

As stated in eqn. (1), complexes can be formed via one or more ligand atoms situated on the same organic residue, $\mathrm{A}$, such as, for instance, a salicylic acid residue of humic acids forming a chelate via carboxylate and phenol oxygen atoms; ${ }^{32}$ then yielding a $\mathrm{CuA}$ species and 2 protons. (In this case, where a proton from a phenolic group is released with a $\mathrm{p} K$-value $>7.5$, and thus outside our range, a detailed formula would be $\mathrm{CuH}_{-1} \mathrm{~A}$, and then $(q+1)$ protons are released.) However, eqn. (1) is also supposed to involve possible complex formation via different organic residues within the same humic acid particle, then yielding species $\mathrm{CuA}_{2}, \mathrm{CuA}_{3}$ and so on. Finally, copper ions may be bound to organic residues in two or more different particles, then denoted as $\mathrm{A}^{*}$, $\mathrm{A}^{* *}, \ldots$. Then a diligandic mononuclear complex of the latter kind may be denoted $(\mathrm{CuA}) \mathrm{A}^{*}$. However, for simplicity eqn. (1) only describes the first case, but the outcome would be the same: a release of protons due to copper ion complex formation.

The complex formation was measured using cells of the following type:

$\mathrm{ME}$ | solution at steady state $\| \mathrm{RE}$

where ME is a glass electrode (Ingold No. U262-S7), a platinum electrode (Ingold No 805-S7), or an electrode sensitive to copper ions (Metrohm No. 60502). RE is a commercial $\mathrm{Ag}, \mathrm{AgCl}$ electrode with double junctions (Metrohm No. 60726) of the type:

$0.1 \mathrm{M} \mathrm{NaClO}_{4} \mid 0.08 \mathrm{M} \mathrm{NaClO}_{4}$,

\section{$0.02 \mathrm{M} \mathrm{NaCl} \mid \mathrm{AgCl}, \mathrm{Ag}$}

At $24^{\circ} \mathrm{C}$ the electromotive forces (emfs) can be represented by the following equations for the cells of the copper electrode, glass electrode and redox electrode, respectively:

$$
\begin{aligned}
& E_{\mathrm{Cu}}=E_{0 \mathrm{Cu}}-29.48 \log b+E_{\mathrm{j}} \\
& E_{\mathrm{G}}=E_{0 \mathrm{G}}+58.96 \log h+E_{\mathrm{j}} \\
& E_{\mathrm{R}}=E_{\mathrm{OR}}-58.96(q / n) \mathrm{pH}+58.96 / n \log \left([\mathrm{A}]^{r} /\left[\mathrm{H}_{q} \mathrm{~A}_{r}\right]\right)
\end{aligned}
$$

Here, $h$ and $b$ are the free concentrations of $\mathrm{H}^{+}$and $\mathrm{Cu}^{\mathrm{II}}$ ions. Eqn. (5) is based on the general redox reaction

$n \mathrm{e}^{-}+q \mathrm{H}^{+}+r \mathrm{~A}^{y-} \rightleftharpoons \mathrm{H}_{q} \mathrm{~A}_{r}^{(q-n-r y)+}$

where $\mathrm{A}^{y-}$ is an electron and proton acceptor of humic acids; $n$ and $q$ are the number of electron and protons involved in the reaction; and the equilibrium sign of eqn. (6) indicates steady states rather than true equilibria. Please note that the last term of eqn. (5) $58.96 / n \log \left([\mathrm{A}]^{r} /\left[\mathrm{H}_{q} \mathrm{~A}_{r}\right]\right)$, will be constant when no redu- 
cing or oxidizing agents are added during an acid-base titration (for simplicity the charges are omitted).

The liquid junction potential, $E_{\mathrm{j}}$, was determined in a separate titration, where a $0.1 \mathrm{M} \mathrm{NaClO}_{4}$ solution was titrated by $\mathrm{HClO}_{4}$. The result was $E_{\mathrm{j}} \approx 400 h$ (cf. Ref. 4). A solution of $1 \mathrm{mM} \mathrm{HClO}_{4}$ in $0.1 \mathrm{M} \mathrm{NaClO}_{4}$ was used for the regular calibration of the glass electrode cell. The slope of the glass electrode cell [then using a $(\mathrm{Ag}, \mathrm{AgCl}$, $3.0 \mathrm{M} \mathrm{KCl}$ ) reference electrode (Ingold No. 363-S7)] was controlled by a series of standard buffers. ${ }^{33}$ The emfs of the cells studied were measured using Guildline digital nanovoltmeters (model 4880A).

We have assumed in regarding eqns. (1) and (3)-(6) as valid that the activity factors are approximately constant in the $0.1 \mathrm{M} \mathrm{NaClO}_{4}$ medium, and that they can be included in the $E_{0}$ constants.

\section{Experimental}

Materials. Humic acids were prepared from an Al horizon, podzol soil taken from a meadow in a suburb of Uppsala. The first steps in the preparation were the same as described previously ${ }^{34}$ involving extraction with $0.05 \mathrm{M}$ pyrophosphate buffer $\mathrm{pH} 7$ (Buffer $\mathrm{P}$ ) followed by precipitation of humic acids at low $\mathrm{pH}$ by $\mathrm{HCl}$. The precipitate was dissolved in $0.15 \mathrm{M}$ Buffer $\mathrm{P}$, and any residue was discarded by centrifugation. Then the procedure of precipitation and dissolving was repeated four times, and the humic acids were finally dissolved in $0.15 \mathrm{M}$ Buffer $\mathrm{P}$ and stored at $-80^{\circ} \mathrm{C}$. In this study the preparation used was further treated in order to eliminate minor concentrations of silicate and metal ions first by dialysis against aq. dest. (distilled water), $0.2 \mathrm{M} \mathrm{HF}$ (for $24 \mathrm{~h}$ ), and then again against aq. dest. Then the sample was dialysed against $0.2 \mathrm{M}$ EDTA of $\mathrm{pH} 7$ followed by aq. dest., and then successively against $0.3 \mathrm{M} \mathrm{HF}, 0.1 \mathrm{M}$ $\mathrm{HCl}$, and aq. dest. The purified humic acids were dissolved in the $0.15 \mathrm{M}$ Buffer $\mathrm{P}$ and then dialysed against this buffer. After prolonged dialysis against aq. dest., samples of humic acids were frozen and kept at $-80^{\circ} \mathrm{C}$. Spectrapor membrane tubing (Los Angeles, USA) was used, with a 3500 mol. wt. cutoff. The final humic acid preparation contained $<1 \%$ silicate, $<0.1 \% \mathrm{Fe},<0.02 \%$ $\mathrm{Ca}$ and $<0.001 \% \mathrm{Cu}$ as calculated on a dry weight basis. The $\mathrm{C} / \mathrm{N}$ quotient was 14.6. The concentration of each solution was obtained via $\mathrm{C}$ analyses assuming a carbon content of 53\% (Ref. 35).

The copper(II) solutions used in this study were obtained from the same batch as that referred to in Ref. 36. The copper and calcium concentrations of the final solutions obtained after the measurements were completed were controlled by analysis. All the other chemicals used were of analytical grade.

Procedure. Complex formation was measured by successively adding samples of $\mathrm{HClO}_{4}$ to a solution of humic acids containing copper(II) and $0.1 \mathrm{M} \mathrm{NaClO}$. An anaerobic atmosphere was maintained with argon from which traces of oxygen were removed by passing it over hot activated copper ${ }^{37}$ and then through a solution of $\mathrm{Cr}^{\text {Ill }}$, then the argon gas was freed from possible acid and base impurities by passing it through solutions of $10 \%$ $\mathrm{NaOH}$ and $10 \% \mathrm{H}_{2} \mathrm{SO}_{4}$, and then finally through two bottles of $0.1 \mathrm{M} \mathrm{NaClO}$ before reaching the titration vessel. The solutions were protected against light and the titrations were made in a dark room kept at $24.00 \pm 0.05^{\circ} \mathrm{C}$.

The data collected from the measurements were scaled to a set of $Z(\mathrm{pH})$ curves. Then the initial solution of only humic acids and $0.1 \mathrm{M} \mathrm{NaClO}_{4}$ was first adjusted to be close to $\mathrm{pH}$ 7. The precise measured $\mathrm{pH}$ then gave the the starting $Z$-value on the acid-base curve, where $Z$ (in $\mathrm{mmol} \mathrm{g}^{-1}$ ) was plotted against $\mathrm{pH}$ (Fig. 2). Then the copper ion solution was added and the $Z$-value was adjusted for the dilution and for the $\mathrm{HClO}_{4}$ in the $\mathrm{Cu}^{\text {II }}$ solution. ${ }^{36}$ The function, $Z$, is defined by

$Z=(H-h) / C_{\mathrm{A}}$

where $H$ is total molar concentration of protons and $C_{\mathrm{A}}$ the concentration of humic acids in $\mathrm{g} \mathrm{l}^{-1}$; thus, $(H-h)$ represents the molar concentration of $\mathrm{H}^{+}$bound to the humic acids.

For each measuring point, it was carefully controlled that the emf of the redox electrode cell obeyed the steadystate line corresponding to that of Fig. 2 in Ref. 16. Then the emf of the copper electrode cell was measured. Usually, a steady state was reached after 6-24 h. After each titration was completed, the solution was carefully checked for any precipitates (sometimes via centrifugation) giving a negative result.

In order to find out whether metal ions diffuse into the humic acid particles or just react with ligands on their surfaces, time-resolved data were recorded. Then the protons, set free as a result of the metal ion reaction, were recorded by measuring $E_{\mathrm{G}}$ [eqn. (4)] as a function of time. In this case $\mathrm{Ca}^{2+}$ was used instead of $\mathrm{Cu}^{\mathrm{II}}$. (The advantage of using calcium ions is that their reactions depend only on charge and ionic size and that the fast kinetics of their reactions ${ }^{38}$ are easily distinguished from diffusion; compared to $\mathrm{Cu}^{\mathrm{II}}$ ions, calcium ions do not undergo redox reactions and they do not form inert complexes, such as charge-transfer complexes, for instance.) Although stirring was provided by Ar bubbling, magnetic stirring was also used at the injection of $\mathrm{Ca}^{\text {Il }}$ ions into the humic acid solution.

\section{Results}

Kinetic data. Figure 1 shows time-resolved data for three different $\mathrm{Ca}^{2+}$ concentrations, where $E_{\mathrm{G}}$ of eqn. (4) is plotted against time. Thus, we measure the protons set free by humic acids as a result of the reactions with calcium ions. These initial kinetic data of the calcium ion interactions with humic acids can be explained by traditional relaxation kinetics as described in Ref. 16 . This yielded the $\tau$-values of $5.9,58.5$ and $130 \mathrm{~s}$ for the 


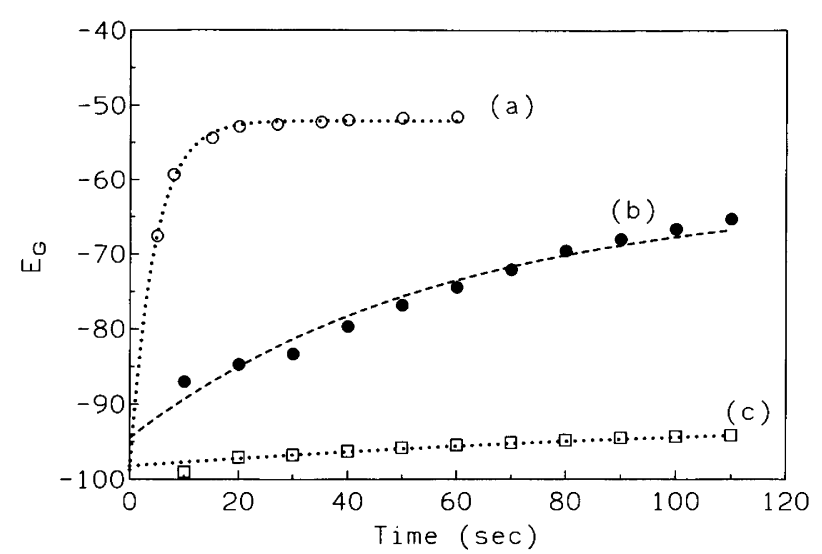

Fig. 1. Time-resolved data for $\mathrm{Ca}^{2+}$ interactions with humic acids. The protons set free by the $\mathrm{Ca}$ " reactions are recorded via the increase in $E_{\mathrm{G}}$ [eqn. (4)] as a function of time. After the addition of calcium ions the total concentrations were: (a) $1.75 \mathrm{mM} \mathrm{Ca}^{2+}, C_{\mathrm{A}}=2 \mathrm{~g} \mathrm{I}^{-1}$; (b) $0.13 \mathrm{mM} \mathrm{Ca}^{2+}, C_{\mathrm{A}}=$ $0.5 \mathrm{~g} \mathrm{I}^{-1}$; (c) $0.033^{\prime} \mathrm{mM} \mathrm{Ca}^{2+}, C_{\mathrm{A}}^{\prime}=0.5 \mathrm{~g} \mathrm{I}^{-1}$.

addition of calcium ions to final concentrations of 1.75 , 0.13 and $0.033 \mathrm{mM}$ in the humic acid solutions, respectively. The processes that might control the overall rate of metal ion-humic acid interactions include: (1) film diffusion through the boundary layer surrounding the humic acid particles; (2) intraparticle diffusion in the matrix of the particles; and (3) reactions at the binding sites of the particles. Since the reactions of calcium ions in general are very fast $(\ll 1 \mathrm{~s}),{ }^{38}$ the slow rates of this study (Fig. 1) indicate that the calcium ion interactions are diffusion-controlled rather than reaction-controlled. The fact that there is a marked increase in the rate of released protons with increasing $\mathrm{Ca}^{2+}$ concentrations indicates that film diffusion rather than intraparticle diffusion is rate limiting, ${ }^{20} \mathrm{cf}$. Ref. 19 . If we compare the Fig. 1 data with those of Fig. 2e in the paper by Bunzl et al. ${ }^{20}$ we find that both sets of data obey the same timescale. As expected, the protons set free (measured in this study) show a slower rate as compared to the absorption of $\mathrm{Ca}^{2+}$ ions by the humic acid particles (measured by Bunzl et al. ${ }^{20}$ ). For instance, $1000 \mu \mathrm{E} \mathrm{Ca}{ }^{2+}$ per $\mathrm{g}$ humic acid yield $t(1 / 2)=6 \mathrm{~s}$ (Ref. 20) as compared to our datum for $1754 \mu \mathrm{E} \mathrm{g}^{-1}$ of $4 \mathrm{~s}$, and $100 \mu \mathrm{E} \mathrm{g}^{-1}$ yield $t(1 / 2)=25 \mathrm{~s}$ (Ref. 20) as compared to our datum of $90 \mathrm{~s}$ for $132 \mu \mathrm{E} \mathrm{g}^{-1}$ ( $\mu \mathrm{E}=$ microequivalents). As a result the kinetic data clearly indicate that bivalent metal ions diffuse into the humic acid particles, where they react and release protons.

Acid-base data. Figure 2 shows the acid-base titrations in the form of the data $Z(\mathrm{pH})$ at constant concentration of humic acids, $C_{\mathrm{A}}$, of 2.0 and $1.0 \mathrm{~g} \mathrm{l}^{-1}$. The data of Fig. 2 show a plateau at $\mathrm{pH} 7.5$ and a tendency to an inflexion point at $\mathrm{pH} 2.9$. Between these two points $2.7 \mathrm{mmol}$ of $\mathrm{H}^{+}$are titrated per $\mathrm{g}$ of humic acid. This is in agreement with earlier studies, where $2.4-3.3 \mathrm{mmol}$ of

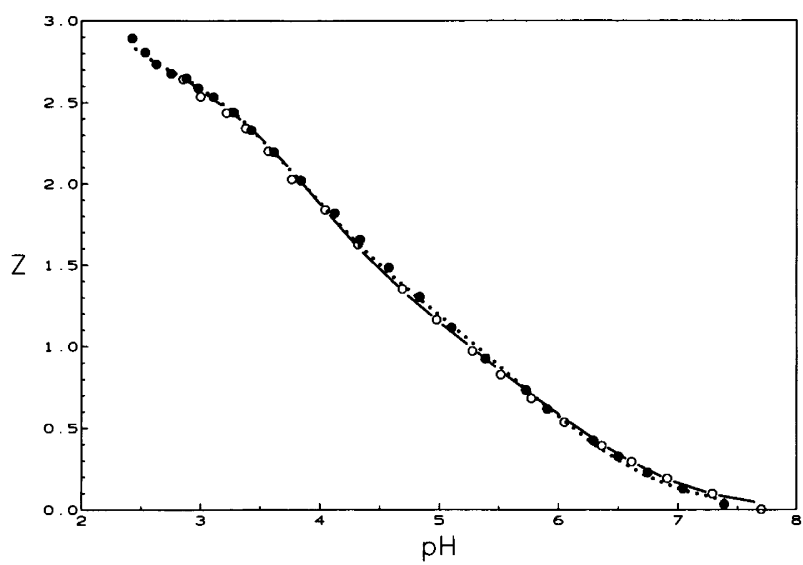

Fig. 2. Proton reactions of humic acids in the plot $Z(\mathrm{pH})_{C_{A^{\prime}}}$ where $Z$ (in $\mathrm{mmol} \mathrm{g}^{-1}$ ) is the average number of protons bound per $C_{\mathrm{A}}$ (in $\mathrm{g}^{-1}$ ). The total concentration of humic acids, $C_{A}$, were: 0,1 and $0,2 \mathrm{~g} \mathrm{I}^{-1}$. The dotted and dashed curves are calculated from eqns. (7), (9), and (10a) using the constants of Set No. 4 in Table 1 for $C_{\mathrm{A}}=1$ and $2 \mathrm{gl}^{-1}$, respectively.

titratable $\mathrm{H}^{+}$per $\mathrm{g}$ of humic acid were reported for the same range. ${ }^{5,6}$

When we analysed the experimental data, we normalized the concentration of acidic groups of humic acid in molar concentration, $A$, so that the value of $Z$ between the two inflexion points would correspond to the highest integer $q / r$ for the species considered. If we assume that at the steady state the following reactions are involved:

$q \mathrm{H}+r \mathrm{~A} \rightleftharpoons \mathrm{H}_{q} \mathrm{~A}_{r}$

with the apparent stability constants, $\beta_{q r}$, then, after normalizing, we define the total concentration of protons, $H$, and ligand, $A$, on the molar scale:

$H=h+\Sigma q\left[\mathrm{H}_{q} \mathrm{~A}_{r}\right]=h+\left(\Sigma q\left[\mathrm{H}_{q} \mathrm{~A}_{r}\right]\right)_{H}$

$A=a+\Sigma r\left[\mathrm{H}_{q} \mathrm{~A}_{r}\right]$

It follows from Fig. 2 that the data for the two different $C_{\mathrm{A}}$ concentrations do not entirely coincide, and that there is a tendency for them to cross over each other. This might indicate that dimers or oligomers are formed in the solution. ${ }^{39}$ It should be noted that the species formally analysed as oligomers are supposed to be due to the formation of internal hydrogen bonds of the particles.

We analysed the composition of the possible species existing in the solution using the general least-squares computer program LETAGROP. ${ }^{40}$ Although true equilibria do not exist in the solutions, we will attempt to describe the steady states observed in the form of apparent 'equilibrium' constants. The error square sum was calculated from the equation:

$U=\left(Z_{\text {calc }}-Z\right)^{2}$

where $Z_{\text {calc }}$ is the calculated $Z$-value. $Z_{\text {calc }}$ was calculated from the $\mathrm{pH}, A$ and assumed $\beta$-values. The result is shown in Table 1. It follows from this table that neither 
Table 1. Analysis of acid-base data from humic acids.

\begin{tabular}{|c|c|c|c|c|c|c|c|}
\hline \multirow{2}{*}{$\begin{array}{l}\text { Set } \\
\text { No. }\end{array}$} & \multicolumn{4}{|c|}{$\log \beta$ for species ${ }^{a}$} & \multirow[b]{2}{*}{$10^{2} \mathrm{U}$} & \multirow[b]{2}{*}{$10^{2} \sigma(Z)$} & \multirow{2}{*}{$\begin{array}{l}\text { No. of } \\
\text { points }\end{array}$} \\
\hline & $\mathrm{HA}$ & $\mathrm{H}_{2} \mathrm{~A}$ & $\mathrm{H}_{3} \mathrm{~A}$ & $\mathrm{HA}_{2}$ & & & \\
\hline 1 & $5.80 \pm 0.06$ & $9.63 \pm 0.06$ & - & - & 7.0 & 4.5 & 37 \\
\hline 2 & $5.81 \pm 0.06$ & $9.61 \pm 0.06$ & $11.21 \pm 0.2$ & - & 6.7 & 4.4 & 37 \\
\hline 3 & $5.81+0.02$ & $9.67+0.03$ & - & $8.59+0.07$ & 0.9 & 1.7 & 37 \\
\hline 4 & $5.82 \pm 0.03$ & $9.66 \pm 0.04$ & $11.3 \pm 0.1$ & $8.57 \pm 0.07$ & 1.2 & $1.7_{5}$ & 43 \\
\hline \multirow{2}{*}{$\begin{array}{l}\text { Set. } \\
\text { No. }\end{array}$} & \multicolumn{3}{|l|}{$\log \beta_{11}=\mathrm{p} K$} & \multirow{2}{*}{$\begin{array}{l}\text { Normalizing } \\
\text { factor/ } \\
\mathrm{mmol} \mathrm{g}^{-1}\end{array}$} & & & \\
\hline & HA & $\mathrm{HB}$ & $\mathrm{HC}$ & & & & \\
\hline 5 & $4.76 \pm 0.06$ & - & - & 2.7 & 43 & 11 & 37 \\
\hline 6 & $5.79 \pm 0.05$ & $3.84 \pm 0.04$ & - & 1.35 & 6.9 & 4.5 & 37 \\
\hline 7 & $6.18 \pm 0.1$ & $4.63 \pm 0.06$ & $3.67 \pm 0.04$ & 0.90 & 3.6 & 3.2 & 37 \\
\hline
\end{tabular}

aNormalizing factor $=1.35 \mathrm{mmol} \mathrm{g}^{-1}$ for the first part of the table.

one single acid-base group nor one single diprotic acid can explain the data (Sets Nos. 5 and 1). Introducing the dimer $\mathrm{HA}_{2}$ yields the best agreement with the experimental data (Set No. 3). Introducing other oligomers, such as $\mathrm{H}_{2} \mathrm{~A}_{2}, \mathrm{H}_{3} \mathrm{~A}_{2}$ and $\mathrm{HA}_{3}$. did not improve the agreement with the experimental data. However, $\mathrm{H}_{3} \mathrm{~A}$, with a $\mathrm{p} K$-value below 2 , yields a certain decrease in the error square sum, $U$ (Set No. 2).

In Table 1 a series of data are also compiled assuming that there are sets of one, two, or three independent monoprotic acid-base groups, supposedly yielding normalized $Z$-values of 1.0, 2.0 and 3.0 between the inflexion points. Although the error square sum successively decreases, the best set involving three such groups (Set No. 7) does not improve the agreement with the data as compared to the dimeric set (Set No. 3). In the final analysis, six further points in the most acid range were also included; as a result, the $\mathrm{H}_{3} \mathrm{~A}$ species becomes better defined (Set No.4). Then, finally, we also varied the factor used to normalize $Z$ using two set values: 1.29 , 1.41 except for 1.35 , which was generally used throughout this analysis. For the 'best' set obtained (for $f=1.35$ ), we finally kept the $\beta$-values constant and varied the factor; the result was $f=1.350 \pm 0.001 \mathrm{mmol} \mathrm{g}^{-1}$. This error of about $0.1 \%$ is less than the experimental error of about $0.2-0.5 \%$. As the result, we can describe the present $Z(\mathrm{pH})$ data by the following apparent 'stability' constants (Set No. 4):

$\log \beta_{11}=5.82, \log \beta_{21}=9.66, \log \beta_{12}=8.57$ and possibly also $\log \beta_{31}=11.3$.

Table 2 shows the 'diprotic' and 'triprotic' constants recalculated to $\mathrm{p} K$-values. In this table are also listed $\mathrm{p} K$-values reported in some other recent publications. ${ }^{4,5,41}$ In the data analysis we have not considered electrostatic factors due to the fact that the particles appear to be penetrable by charged ions. Also, in the detailed analysis made by Bolton et al. ${ }^{5}$ the consideration of electrostatic factors did not improve the agreement with the experimental data as compared to the analysis made in the absence of these factors. Likewise, further
Table 2. Apparent $\mathrm{p} K$-values and $\log \beta_{12}$-value for humic acids.

\begin{tabular}{llllll}
\hline Reference & $\mathrm{p} K(\mathrm{HA})$ & $\begin{array}{l}\mathrm{p} K \\
\left(\mathrm{H}_{2} \mathrm{~A}\right)\end{array}$ & $\begin{array}{l}\mathrm{p} K \\
\left(\mathrm{H}_{3} \mathrm{~A}\right)\end{array}$ & $\begin{array}{l}\mathrm{p} K \\
\left(\mathrm{H}_{4} \mathrm{~A}\right)\end{array}$ & $\log \beta_{12}$ \\
\hline Bolton et al. ${ }^{5}$ & 5.31 & 4.0 & - & - & - \\
${\text { Wahlberg } \text { et }_{\text {al. }}{ }^{4}}^{41}$ & 5.4 & 4.0 & - & - & - \\
${\text { Leenheer } \text { et } \text { ll. }^{41}}$ & 5.6 & 4.3 & 3.3 & 1.7 & - \\
Present study $^{\mathrm{a}}$ & 5.8 & 3.85 & 1.6 & - & 8.57 \\
\hline
\end{tabular}

${ }^{a}$ Set No. 4 in Table 1.

parameters could have been introduced corresponding to the concentration of each acid-base group. However, the experimental data are very well described by only four parameters (Fig. 2), and in the study of Bolton et al. ${ }^{5}$ the difference in concentration among the groups was small in the present $\mathrm{pH}$ range.

Table 2 shows that there are certain agreements among the four different studies listed (especially regarding a $\mathrm{p} K$-value of about 4 ), although soil sources, preparation, experimental conditions and $\mathrm{pH}$ scale are different. In the most acid range, our $\mathrm{p} K$ of 1.6 shows agreement with that of Leenheer et al., ${ }^{41}$ who reported $\mathrm{p} K=1.7$. The $\mathrm{p} K$-value of 5.8 observed by us might be an internal carboxylate group within the humic acid particles where the environment most likely is more hydrophobic as compared to the bulk solvent. This idea is supported by a study of the $\mathrm{p} K$-value of a peptide carboxyl group in a methanol medium, which yielded $\mathrm{p} K=5.66$ compared to $\mathrm{p} K=3.35$ in an aqueous medium. ${ }^{42} \mathrm{~A}$ dimer of the kind shown in Table 1 has recently been reported by Bergelin et al.;3 however, they used humic substances obtained by just an 'extraction' from soil.

It should be noted that $\mathrm{p} K$-values reported in the range $\mathrm{pH} 7 \pm 0.5$ by other authors are not listed. According to our observations, protons are slowly released spontaneously from humic acids in this range. Simultaneous degradation into smaller particles occurs as indicated by penetration of humic material through the membrane during dialysis. We tried to overcome this 
obstacle in our study by using prolonged dialysis at $\mathrm{pH} 7$ and by retaining particles of higher molecular mass.

\section{Copper ion reactions}

Data $\mathrm{Z}(p H)_{\mathrm{C}_{A}, \mathbf{B}}$. Figure 3 shows two sets of $Z$-curves for the humic acid concentrations 2 and $1 \mathrm{~g}^{-1}$ obtained by titrations in the presence of approximately constant $\mathrm{Cu}^{\mathrm{II}}$ ion concentrations, $B=0.13,0.24,0.33 \mathrm{mM}$ and $0.12,0.16 \mathrm{mM}$, respectively. It follows from this figure that the $Z$-data obtained in the presence of copper ions do not show any tendency to coincide with those recorded in the absence of $\mathrm{Cu}^{\mathrm{II}}$ ions. At low $\mathrm{pH}$ and at relatively fast kinetics the competition with protons usually leads to that $Z$-curves tend to coincide with that of the acid-base curve. ${ }^{36,44}$ This is not valid for the present $Z$-data (Fig. 3), and therefore, as a first approximation, we will assume that the major copper ion concentration is inertly bound to humic acids.

The number of bound protons may be described by

$Z C_{\mathrm{A}}=\left(\Sigma q\left[\mathrm{H}_{q} \mathrm{~A}_{r}\right]+\Sigma q\left[\mathrm{Cu}_{p} \mathrm{H}_{q} \mathrm{~A}_{r}\right]\right)_{B}$
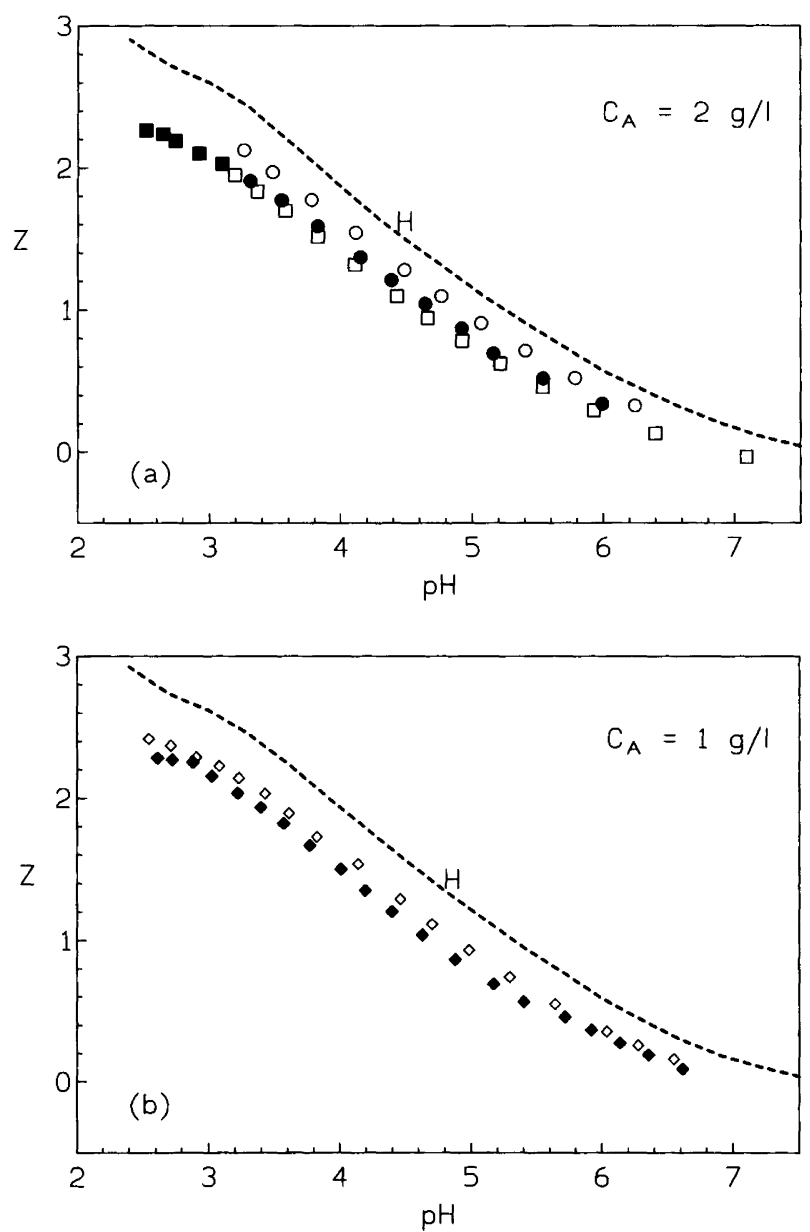

Fig. 3. The average number of protons bound per $C_{\mathrm{A}}, Z$, plotted as a function of $\mathrm{pH}$ for approximately constant $C_{\mathrm{A}}$ and $B$ (the total $C u^{\prime \prime}$ concentration). (a) $\bigcirc, B=0.13 \mathrm{mM}$; - $B=0.24 \mathrm{mM} ; \square, B=0.33 \mathrm{mM}$ (titration No. 1); $\square, B=$ $0.33 \mathrm{mM}$ (titration No. 2). (b) $\diamond, B=0.12 \mathrm{mM} ; \diamond, B=$ $0.16 \mathrm{mM}$.
For a constant $\mathrm{pH}$ the concentration of protons set free due to complex formation may then be calculated from

$$
\begin{aligned}
\left(Z_{\mathrm{H}}-Z_{\mathrm{M}}\right) C_{\mathrm{A}}= & \left\{\Delta Z\left(C_{A}\right)\right\}_{h} \\
= & \left\{\left(\Sigma q\left[\mathrm{H}_{q} \mathrm{~A}_{r}\right]\right)_{H}\right. \\
& \left.-\left(\Sigma q\left[\mathrm{H}_{q} \mathrm{~A}_{r}\right]+q\left[\mathrm{Cu}_{p} \mathrm{H}_{q} \mathrm{~A}_{r}\right]\right)_{B}\right\}_{h}
\end{aligned}
$$

where $Z_{\mathbf{H}}$ and $Z_{\mathbf{M}}$ are the $Z$-values recorded in the absence and in the presence of $\mathrm{Cu}$ ions, respectively. According to eqn. (1), the number of protons released per copper ion, $(q r) \mathrm{H}^{+}$should be related to the number of ligand atoms bound to copper ions in the $\mathrm{Cu}_{p} \mathrm{~A}_{r}$ species. The average number of protons released per $B$ at constant $\mathrm{pH},\left\{\Delta Z\left(C_{\mathrm{A}}\right) / B\right\}_{h}$, would then correspond to the average number of acid-base groups involved in the copper binding as calculated per copper ion.

In Fig. 4 the quantity $\left\{\Delta Z\left(C_{\mathrm{A}}\right) / B\right\}_{h}$ is plotted against $\mathrm{pH}$. It follows from this figure that for the highest $C_{\mathrm{A}^{-}}$ value and the two lowest $B$-values, the number of protons released per copper ion reaches 4 as the $\mathrm{pH}$ decreases. For the highest $B$-values and for the lower $C_{\mathrm{A}}$-value the number of released protons is on average more than three but less than four. This may be explained by the assumption that four ligand atoms bind the copper ion at high $C_{\mathrm{A}}$ and low $B$, and also, to a certain extent, at the other concentrations. Thus, there seems to be a certain number of four-coordinate sites in humic acids $\left(\geqslant 0.1 \mathrm{mmol} \mathrm{g}^{-1}\right)$ where four protons are released as a result of $\mathrm{Cu}$ binding; thus, in good agreement with a coordination number four both for $\mathrm{Cu}^{\mathrm{II}}$ and $\mathrm{Cu}^{\mathrm{I}}{ }^{45} \mathrm{~A}$ support for the idea that the $\mathrm{Cu}$ ions are mainly bound inertly is that these copper ions show no tendency to dissociate from their coordinated groups due to competition with protons (Fig. 3). Also, the data recorded using the $\mathrm{Cu}$-ion-sensitive electrode (Fig. 5) indicate a low free copper ion concentrations in the whole range.

Data $\log \mathrm{B} / \mathrm{b}(p H)_{\mathrm{C}_{A}, \mathrm{~B}}$. Figure 5 shows the data obtained by the copper-ion-sensitive electrode in the plot

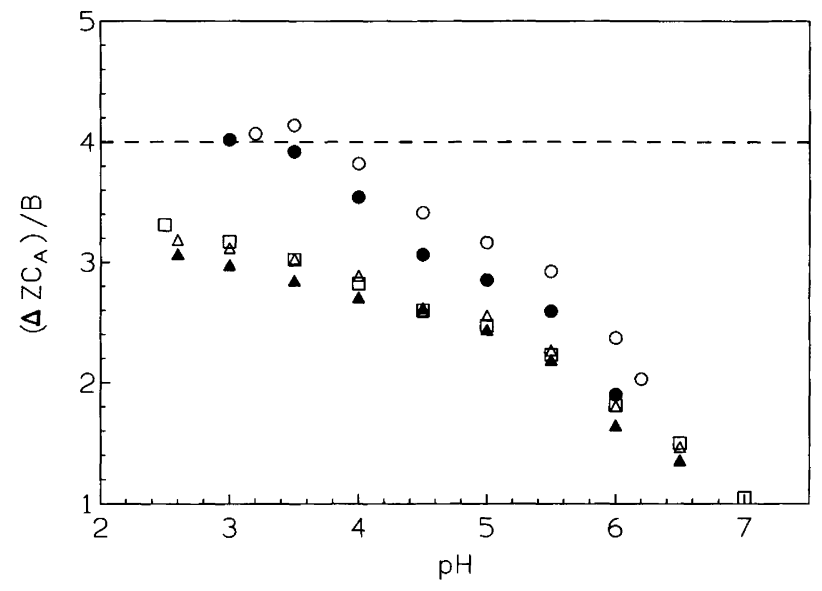

Fig. 4. The number of protons set free per $C u^{\prime \prime}$ ion, $\left(\Delta Z C_{A}\right) / B$ plotted against $\mathrm{pH}$. For $C_{\mathrm{A}}=2 \mathrm{~g} \mathrm{I}^{-1}$ the symbols are the same as in Fig. 3a; for $C_{\mathrm{A}}=1 \mathrm{~g} \mathrm{I}^{-1}$ and $B=0.12 \mathrm{mM}, \triangle$; and for $B=0.16 \mathrm{mM}, \Delta$. 


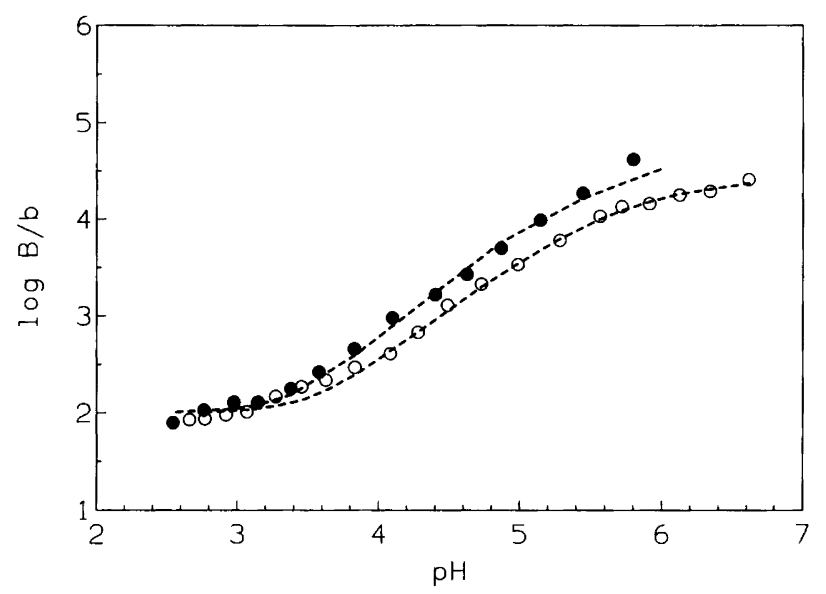

Fig. 5. Data $\log B / b$ as a function of $\mathrm{pH}$ for approximately constant total concentration of humic acids, $C_{A}$, at $1 \mathrm{~g} \mathrm{I}^{-1}$, $\bigcirc(B=0.16 \mathrm{mM})$; and at $2 \mathrm{gl}^{-1}, \bigcirc(B=0.33 \mathrm{mM})$. The curves were calculated assuming one single complex, CuA, with $\log \beta_{1}=5.3$ as described in the text.

$\log B / b$ as a function of $\mathrm{pH}$ at constant $C_{\mathrm{A}}$ and $B$. These data were calculated via eqn. (3) using the relationship:

$\log B / b=\left(E_{\mathrm{Cu}}-E_{B}\right) / 29.48$

where $E_{B}$ is the emf recorded for a solution of $B \mathrm{mM}$ $\mathrm{Cu}$ ions in the absence of humic acids.

It follows from Fig. 5 that the data become independent of $\mathrm{pH}$ when $\log B / b$ approaches 2 . We believe that this is due to the fact that most of the copper ions are inertly bound and that the copper sensitive electrode only records labile copper ions. When $\log B / b \approx 2$, we then obtain for the labile $\mathrm{Cu}$ ion fraction: $B$ (labile)= $B^{*}=b$. Thus, the labile fraction is about $1 \%$ of $B$. From the two sets of data in Fig. 5 we estimate for $\mathrm{pH} 4-5.5$ :

$\left[(\Delta \log B / b) / \Delta \log C_{\mathrm{A}}\right]_{\mathrm{pH}} \approx 1$

and then for $\mathrm{pH} 3.5-5$ :

$[(\log B / b) / \Delta \mathrm{pH}]_{C_{\mathrm{A}}} \approx 1$

These results indicate that the data can be explained by one single $\mathrm{CuA}$ species. Then

$B^{*}=b+[\mathrm{CuA}]=b+a b \beta_{1}$
$A^{*}=a+a \Sigma h^{q} \beta_{q 1}+2 a^{2} h \beta_{12}+a b \beta_{1} \approx a\left(1+\Sigma h^{q} \beta_{q 1}\right)$

where $A^{*}$ is the value of $A$ corrected for inertly bound $\mathrm{Cu}$ ions and $A$ (on molar scale) is obtained from $C_{\mathrm{A}}$ via the factor, $1.35 \mathrm{mmol} \mathrm{g}^{-1}$ (see p. 176). $\beta_{1}$ is the stability constant for the reaction [cf. eqn. (1)]:

$\mathrm{Cu}^{2+}+\mathrm{A}^{2-} \rightleftharpoons \mathrm{CuA}$

where the charge of $\mathrm{A}^{2-}$ tentatively is set to -2 . For $b \ll B^{*}$ and $a \ll A^{*}$ we find

$\log B^{*} / b \approx \log A^{*}+\log \left(\Sigma h^{q} \beta_{q 1}\right)^{-1}+$ const.

$\approx \log A^{*}+\mathrm{pH}+$ const.
Thus it follows from eqn. (14b) that, under the given conditions (the $A^{*}$-values differ by a factor of 2 ), the existence of a single $\mathrm{CuA}$ species would approximately give partial derivatives corresponding to the difference quotients observed. As follows from Fig. 5, theoretical curves calculated assuming one single $\mathrm{CuA}$ species are in good agreement with the data; the curves were calculated from $\log \beta_{1}=5.3$ using eqns. (10b) and (14a), the data of Fig. 4, and the acid-base constants (Table 2).

The present results also give an idea regarding what groups might be involved in binding the labile $\mathrm{Cu}$ ions. The fact that the $\log B / b$ data tend to level off at $\mathrm{pH} 5.5$ indicates that most likely carboxylate groups are involved. However, the value of $\log \beta_{1}=5.3$ is considerably larger than that recorded for low-molecular-weight carboxylates (e.g. $\log \beta_{1}=1.76$ was reported in Ref. 44). The present relatively large $\beta_{1}$-value may then be ascribed to a bidentate coordination involving two carboxylate groups; for malonic acid, for instance, the $\log \beta_{1}$-values reported $^{46}$ range from 5.0 to 5.6.

\section{Discussion}

The results described in the previous section indicate that humic acids mainly form complexes with copper ions that are characterized by a very slow rate of dissociation, i.e. the $\mathrm{Cu}$ complexes are inert. (However, a minor fraction of the copper ions, about $1 \%$ of $B$, seems to form a labile $\mathrm{CuA}$ complex with $\log \beta_{1}=5.3$ ). We believe that the inert complex formation is due to the fact that the copper ions diffuse into the humic acid particles, and there bind to sites from which they may not readily be released. A support for this idea is the kinetic data of Fig. 1, which indicate that the rate-limiting step for the metal ion-humic acid interaction is diffusion-controlled rather than reaction-controlled. In addition, the rate increases with increasing metal ion concentration (Fig. 1), and this is in agreement with the rate-limiting step being based on film diffusion rather than intraparticle diffusion. ${ }^{20}$ Considering the different conditions, our data are in good agrement with those of Bunzl et $a .^{20}$ It seems likely that the metal-ion diffusion is possible owing to the high water content of humic acid particles; as indicated by the fractal dimension $2.3,{ }^{14}$ they contain $>92 \%$ water. Although $\mathrm{Ca}^{2+}$ ions were used in the kinetic part of this study, the result obtained regarding the diffusion into the particles may also apply to $\mathrm{Cu}^{\text {II }}$ ions. According to the law of ionic diffusion, which is a function of the concentration gradient, the induced electric field, and the diffusion coefficients (cf. eqn. 35 in Ref. 19), the mechanism of diffusion would be similar for different bivalent metal ions. However, once the bivalent ions are inside the particles, then the coordination reactions may be different. The calcium ions would prefer oxygen donors such as carboxylates. Likewise, $\mathrm{Cu}^{\text {II }}$ ions may also form complexes involving oxygen donors, which are the ones most frequently occurring among humic acids. However, $\mathrm{Cu}^{\mathrm{II}}$ ions generally prefer 
nitrogen to oxygen donor atoms and, perhaps, as favoured by the less hydrophilic environment, they may be involved in redox reactions and charge-transfer complexes (cf. p. 314 in Ref. 45).

As shown by Fig. 4, four protons are released per copper ion for $B \leqslant 0.24 \mathrm{mM}$ and $C_{\mathrm{A}}=2 \mathrm{~g} \mathrm{l}^{-1}$, which indicates that the $\mathrm{Cu}$ complexes may be four-coordinate. Within a particle, the distances between the various dentate groups might be small, so that complex formation involving ligand atoms from different regions of the same particle is made possible; for instance, one formed by two chelates each of which contains a carboxylate and an adjacent phenol group. ${ }^{32}$ The release of two protons for $B=0.11 \mathrm{mM}$ at a $\mathrm{pH}(6.2)$ higher than the highest reported $\mathrm{p} K$ (5.8) supports this idea (Fig. 4). Such a complex would be denoted $\mathrm{CuA}_{2}$ (in detail $\mathrm{CuH}_{-2} \mathrm{~A}_{2}$ ) using the notation described on p. 173. However, as indicated above in the previous paragraph, many other kinds of complexes are also possible, and three or four different groups may be involved, such as $\mathrm{CuA}_{3}$ (in detail $\mathrm{CuH}_{-1} \mathrm{~A}_{3}$ ) or $\mathrm{CuA}_{4}$. The fact that $\Delta Z$ increases with decreasing $\mathrm{pH}$ might be surprising (Fig. 4). However, the four-coordinate complexes are most likely already formed at neutral $\mathrm{pH}$. Then when the $\mathrm{pH}$ is decreased into the $\mathrm{p} K$ region of some of the dentate groups, say carboxylates, the protons cannot bind to these groups owing to the strong competition with the copper ions; as a result, $\Delta Z$ increases.

When the present humic acid particles dissolve into aqueous solution, a homogenous solution is formed, for instance, as indicated by small-angle neutron scattering. ${ }^{14,15}$ Nevertheless, the colloidal size and the high water content of the particles makes it possible for metal ions to diffuse into these particles. Thus, in this respect the system becomes a two-phase system, since the intraparticle bivalent metal ions are not in equilibrium with those in the bulk solvent. However, as indicated by our $\log B / b$-data (Fig. 5), the copper ions also form labile complexes most likely involving ligand groups on the surfaces of the particles. As a result, the metal ions are involved both in reactions within the particles and on their surfaces; thus, they are distributed over two phases, one phase of which involves metal ions showing a very slow rate of dissociation. An estimate of the true composition of the complexes and their stability constants of formation then only seems possible for those related to the bulk solvent (see p. 178), since the intraparticle complexes are inert and present in another phase.

This study shows the importance of kinetic data for the understanding of metal ion-humic acid interactions. In many of the earlier studies on this subject, the authors have not been aware of the slow kinetics, and they have used an impenetrable model in their data analysis, see e.g. Refs. 13, 22 and 23. Nevertheless, Hering and $\mathrm{Morel}^{47}$ reported one single 'strong' $\mathrm{Cu}$ complex occupying $0.05 \mathrm{mmol} \mathrm{g}^{-1}$ humic acid, which may correspond to the present four coordinate complex occupying $0.1 \mathrm{mmol} \mathrm{g}^{-1}$. Also, a species of the type $\mathrm{MH}_{-1} \mathrm{~A}$ has been reported repeatedly, ${ }^{5,10,32}$ indicating a chelate formed via carboxylate and phenol oxygen atoms as well as chelates formed via two carboxylates, ${ }^{23,32}$ thus, both these kinds of binding sites are in qualitative agreement with this work. Regarding fulvic acid, the fractal dimension of the particles are not known. Here the situation might be different, although the kinetics of the proton reactions ${ }^{4}$ indicate a fairly close relationship with humic acids.

Regarding the possible environmental implications of this study, it should first be pointed out that in the present titrations, going from $\mathrm{pH} 7$ to $\mathrm{pH} 2.6$, we wanted to simulate how humic matter might react when they are subjected to acid rain. Our relatively low copper ion concentrations, $0.12-0.33 \mathrm{mM}$, are within the range that could exist in polluted soil. Since the data are internally consistent, we believe that a similar situation as we report here would occur at even lower concentrations of copper ions, down to that existing 'normally' in the soil. However, the present preparation of humic acids is highly purified, and considerable amounts of interacting compounds and ions were eliminated from the naturally occurring humic substance, such as silicate and iron ions. Certain precautions should therefore be exercised before any final, environmental conclusions are drawn from this work. Nevertheless, a few points may be emphasized.

A well known drawback with increased acidity in the environment is that metal ions such as aluminium ions are released in a large concentration and they may interfere with the normal uptake of physiological metal ions in the plant kingdom. Here, we report that this effect might be increased when $\mathrm{Cu}$ ions are bound to humic acids, since they may inertly occupy some of the binding sites available. On the other hand, a possible environmental benefit would be that the bioavailability of copper ions may not be increased as a result of acid rain, and thus that an area of copper pollution may be less dangerous for the plant kingdom, even if the soil $\mathrm{pH}$ is in the acid range.

Acknowledgements. We are grateful to The Swedish Agricultural Sciences Research Council, SJFR, for financial support.

\section{References}

1. Frimmel, F. H. and Christman, R. F., Eds. Humic Substances and Their Role in the Environment, Wiley, New York 1988.

2. Hayes, M. H. B., MacCarthy, P., Malcolm, R. L. and Swift, R. S., Eds. Humic Substances II, Wiley, New York 1989.

3. Perdue, E. M. and Gjessing, E. T., Eds. Organic Acids in Aquatic Ecosystems, Wiley, New York 1990.

4. Wahlberg, O. and Agren, S. Acta Chem. Scand. 50 (1996) 561.

5. Bolton, K. A., Sjöberg, S. and Evans, L. J. Soil Sci. Soc. Am. J. 60 (1996) 1064.

6. Young, S. D., Bache, B., Welch, H. A. and Andersson, H. A. J. Soil Sci. 32 (1981) 579.

7. Milne, C. J., Kinniburgh, D. G., De Wit, J. C. M., Van 
Riemsdijk, W. H. and Koopal, L. K. Geochim. Cosmochim. Acta 59 (1995) 1101.

8. Stevenson, F. and Chen, Y. Soil Sci. Soc. Am. J. 55 (1991) 1591.

9. Ephraim, J. H. and Allard, B. Environ. Int. 20 (1994) 89.

10. Marinsky, J. A., Gupta, S. and Schindler, P. J. Colloid. Interface Sci. 89 (1982) 412

11. Boggs, S., Livermore, D. G. and Steitz, M. G. Rev. Macromol. Chem. Phys. C25 (1985) 599.

12. Sposito, G. CRC Crit. Rev. Environ. Ctrl. 16 (1986) 193.

13. Tipping, E. and Hurley, M. A. Geochim. Cosmochim. Acta 56 ( 1992) 3627

14. Österberg, R. and Mortensen, K. Eur. Biophys. 12 (1992) 163.

15. Österberg, R., Mortensen, K. and Ikai, A. Naturwissenschaften 82 (1995) 137.

16. Österberg, R. and Shirshova, L. Geochim. Cosmochim. Acta 61 ( 1997$) 4599$.

17. Musso, H. In: Taylor, M., Batterby, H. R., Eds. Oxidative Coupling of Phenols, Marcel Dekker, New York 1967, pp. 1-94.

18. Eigen, M. and Matthies, P. Chem. Ber. 94 (1961) 3309.

19. Kadelek, R. H. and Keoleian, G. A. In: Fuchsman, C. H., Ed. Peat and Water. Elsevier, New York 1986, pp. 64-93.

20. Bunzl, K., Schmidt, W. and Sansoni, B. J. Soil. Sci. 27 (1976) 32

21. Sposito, G., Holtzclaw, K. M., Le Vesque-Madore. C. S. L. Soil Sci. Soc. Am. J. 42 (1978) 600.

22. Marinsky, J. A. and Ephraim, J. Environ. Sci. Technol. 20 (1986) 349.

23. Bartschat, B. M., Cabanis, S. E. and Morel, F. M. M. Environ. Sci. Technol. 26 (1992) 284

24. Österberg, R. and Mortensen, K. Radiat. Environ. Biophys. 33 (1994) 269.

25. Ikai, A. and Österberg, R. Scanning Microscopy 10 (1996) 994.

26. Fuchsman, C. H. Ed. Peat, Industrial Chemistry and Technology, Academic Press, New York 1980, pp 174-175.
27. Bunzl, K. J. Soil. Sci. 25 (1974) 343.

28. Bunzl, K. J. Soil Sci. 25 (1974) 517

29. Plesset, M. S., Hefferich, F. and Franklin, J. N. J. Chem. Phys. 29 (1958) 1064.

30. Hefferich, F. and Plesset, M. S. J. Chem. Phys. 28 (1958) 418.

31. Hefferich, F. J. Phys. Chem. 66 (1962) 39.

32. Gamble, D. S., Schnitzer, M. and Hoffman, I. Can. J. Chem. 48 (1970) 3197.

33. Bates, H. Electrometric pH Determinations. John Wiley, New York 1954.

34. Österberg, R., Szajdak, L. and Mortensen, K. Environ. Int. 20 (1994) 77.

35. Lindqvist, I. Swed. J. Agric. Res. 12 (1982) 105.

36. Österberg, R. and Sjöberg, B. J. Biol. Chem. 243 (1968) 3038.

37. Meyer, F. R. and Ronge, G. Angew. Chem. 22 (1939) 637.

38. Eigen, M. Pure Appl. Chem. 6 (1963) 97.

39. Ingri, N. Acta Chem. Scand. 17 (1963) 597.

40. Ingri, N. and Sillen, L. G. Acta Chem. Scand. 16 (1962) 173.

41. Leenheer, J. A., Wershaw, R. L. and Reddy, M. M. News Letter of the International Humic Substance Society No. 12 (1994) 9.

42. Österberg, R. J. Phys. Chem. 73 (1969) 2230.

43. Bergelin, A., Wahlberg, O. and Ågren, S. Acta Chem. Scand. 51 (1997) 974.

44. Österberg, R. and Toftgárd, B. Bioinorg. Chem. 1 (1972) 295.

45. Österberg, R. Coord. Chem. Rev. 12 (1974) 309.

46. Sillen, L. G. and Martell, A. E. Stability Constants of Metal-Ion Complexes, Chem. Soc. Spec. Publ. No. 25, 1971.

47. Hering, J. and Morel, F. M. M. Environ. Sci. Technol. 22 (1988) 1234.

Received June 24, 1998 